\title{
Indirect costs associated with "free" paediatric haemodialysis: Experience from Karachi, Pakistan
}

\author{
ALI ASGHAR ANWAR LANEWALA, SUALEHA SIDDIQ SHEKHANI
}

\begin{abstract}
Treatment of children with end-stage kidney disease (ESKD), requiring maintenance dialysis, poses unique challenges. In low- and middle-income countries, lifelong treatment leads to significant stress on the overall family unit. Families face serious financial, social and psychological consequences despite free treatment. This pilot study, utilising primarily quantitative methods, supplemented by two case studies, is set in Sindh Institute of Urology and Transplantation, a tertiary care hospital in Karachi, Pakistan, providing free medical treatment. Fifty-two caretakers of children receiving haemodialysis for more than five years participated in the quantitative arm. Findings reveal that additional financial challenges may send the entire household into financial catastrophe. Social problems include migration from native cities, impact on the education of the sick child along with changes in lives of siblings. One-third of primary caretakers screened positive for anxiety/depression. Healthcare professionals practising in developing countries face considerable ethical dilemmas in their practice when offering "free" paediatric dialysis services knowing the financial and psychological burden imposed on families.
\end{abstract}

Keywords: Indirect costs, paediatric haemodialysis, financial catastrophe, familial burdens, Pakistan

\section{Introduction}

Significant medical advancements have enabled physicians

Authors: Ali Asghar Anwar Lanewala (corresponding author alilanewala@yahoo.com), Professor, Department of Pediatric Nephrology, Sindh Institute of Urology and Transplantation (SIUT), Karachi, Pakistan; Sualeha Siddiq Shekhani (shekhanisualeha@gmail.com), Assistant Professor, Centre of Biomedical Ethics and Culture, Sindh Institute of Urology and Transplantation (SIUT), Karachi, Pakistan.

To cite: Lanewala AA, Shekhani SS. Indirect costs associated with "free" paediatric haemodialysis: Experience from Karachi, Pakistan. Indian J Med Ethics. Published online first on January 21, 2022. DOI: 10.20529/IJME. 2022.006.

Manuscript Editor: Sandhya Srinivasan

Peer reviewers: Two anonymous reviewers

Copyright and license

CIndian Journal of Medical Ethics 2022: Open Access and Distributed under the Creative Commons license (CC BY-NC-ND 4.0), which permits only non-commercial and non-modified sharing in any medium, provided the original author(s) and source are credited. to provide life-saving treatment to children suffering endstage kidney disease (ESKD). Dialysis has improved longterm survival among children with kidneys functioning at less than $15 \%$ (1). While the treatment of choice for ESKD is renal transplantation providing a better quality of life and long-term survival (2), some patients may not be eligible to receive it $(3,4)$. The other medical option is maintenance haemodialysis (HD), which poses different medical and social challenges not only for treating physicians, but also for the entire family unit (5).

Haemodialysis requires commuting to a dialysis unit twice or thrice per week, with each session lasting for 3 to 4 hours (6). Among children, HD poses additional challenges since they have to be accompanied to the unit by adult family members, who are compelled to leave their daily routine. Furthermore, these children require extra care at home, and medical emergencies may necessitate unscheduled hospital visits (7). Researchers have identified multiple stressors affecting caregivers including physical (8), psychological (9), social (10-11) and financial (8) pressures.

In general, healthcare is more accessible in the developed world compared to many low- and middle-income countries (LMICs) due to coverage under the welfare system or health insurance (12). The social service department of the dialysis unit may, if deemed necessary, provide cost of dialysis including transportation to the centre, as evidence from the United States suggests (12).

Within LMICs, access to healthcare is extremely limited. Expenditure on health in India was a mere $3.53 \%$ of the Gross Domestic Product (GDP) in 2017-18 whereas in Pakistan, it stood at $2.90 \%$ (13). The healthcare system in such countries is deeply fragmented with scattered healthcare services provided by the public sector. The governments have relinquished a major share of the responsibility of healthcare to the private sector, which charges high prices. In 2015, 24.3\% of the Pakistani population lived below the poverty line (14), with out-ofpocket expenditure on health in 2018 amounting roughly to $60.24 \%$ (15).

The comparative cost of dialysis and transplant in many developing countries is low yet remains unaffordable for a majority of the population. For instance, cost of dialysis and transplant in India, is one-twentieth of that in the USA (14), but affected households are often driven into poverty due to 
high out-of-pocket expenditure associated with Renal Replacement Therapy (16).

Even among the few with access to subsidised healthcare or free treatment, rates of attrition tend to be high (17-19). This is because indirect costs such as productivity losses for patients and families are not included in economic evaluations $(20,21)$. Even a brief period of dialysis may lead to significant financial strain. For instance, $80 \%$ of families awaiting transplantation in a subsidised care centre in India reported catastrophic health expenditure (22).

Families and caregivers also have to contend with other issues since ESKD does not only affect the patient, but the entire family unit. This is felt more profoundly in the case of paediatric dialysis. The development of ESKD among children has been described as a "life-changing tragedy for the child, their family and their community." (23)

Therefore, the ethical implications for providing free dialysis services for children are profound. Several international surveys have indicated that paediatric nephrologists consider impact on the family unit before initiating, continuing or foregoing dialysis (24-26). In another study from Europe, one of the major reasons for withholding or withdrawing dialysis treatment included considering impact on families (27).

In Pakistan, an LMIC in South Asia, there is no universal health coverage for dialysis services although some healthcare centres provide these services either at a subsidised cost, or completely free of cost. At a free-of-cost healthcare setting in Pakistan, cost of expenditure on dialysis has been estimated to be US\$1680 per year in 2009, although recent estimates suggest that it has increased to $\$ 2000$ per person (28). Limited local literature is available documenting caregiver's burden for patients receiving dialysis treatment. For example, in a study conducted in Rawalpindi, $65 \%$ of 164 caregivers demonstrated mild to moderate caregiver burden (29). However, to the best of the authors' knowledge, no study has been undertaken that looks at the impact on the overall functioning of the family unit within the context of paediatric dialysis in Pakistan.

This pilot study, undertaken in Sindh Institute of Urology and Transplantation (SIUT), a public sector hospital in Karachi, Pakistan, explores the social, economic and psychological impact on families of paediatric patients receiving "free" maintenance haemodialysis. The findings from this study bring to the forefront the ethical dilemmas that clinicians practising within resource-constrained settings face. Moreover, the results of this study are useful from a health policy perspective since they look beyond the usual "financial" and "direct" costs and consider the overall impact on the family unit.

\section{Methods \\ Study design}

The pilot study utilised a mixed method of data collection involving a cross-sectional survey with caregivers of paediatric patients on haemodialysis. We also present to you two case studies in order to provide a deeper insight into the struggles of families whose lives have drastically changed after the initiation of dialysis treatment.

This study is part of the thesis undertaken to fulfil the requirements for the Master's in Bioethics (MBE) by the first author $(A L)$ from the Centre of Biomedical Ethics and Culture (CBEC), SIUT, Karachi, Pakistan.

\section{Study site}

This study was carried out in the haemodialysis unit of SIUT, which has more than 160 stations that provide dialysis round the clock, 6 days a week. The hospital policy dictates no patient is denied treatment. About 80,000 sessions were performed on children below 18 years of age in 2016 (30).

\section{Participant recruitment and selection}

The study used non-probability sampling for recruitment in both quantitative and qualitative arms. Participants were considered eligible if they were the primary caretakers of children less than 18 years of age at the time of initiation of dialysis, and receiving regular maintenance dialysis for more than a year. Only those children who were not candidates for live-related kidney transplant, either due to non-availability of a primary organ donor or to having a primary disease with a high rate of recurrence, were included. Fifty-five primary caretakers met the inclusion criteria. Three however, refused to take part in the study therefore responses were collected from 52 primary caregivers. One primary caregiver (the mother) did not provide any information regarding the father since he had left her after the child fell ill. Therefore, data for 51 fathers is documented. Out of those 52 primary caregivers, two families facing extraordinary challenges after the initiation of dialysis treatment were asked for additional information through informal interviews presented as case studies.

\section{Data collection}

Quantitative data were collected in two ways. One included a researcher-administered questionnaire drawn up specifically for this study containing close-ended questions about the social, educational and financial status of patient, parents and siblings. The other tool was a screening questionnaire known as Aga Khan University-Anxiety Depression Scale (AKU-ADS) validated within Pakistani population to screen primary caretakers for anxiety and depression (31). The first two approaches collectively took about 30 minutes per participant, in which participants provided more sensitive information, captured wherever necessary within the findings.

For case studies, two informal interviews were conducted with primary caretakers, which took approximately one hour each.

\section{Ethical concerns}

Ethics approval for the study was provided by the 
Institutional Review Board (IRB) at SIUT. Written informed consent from the primary caretakers and verbal assent from adolescents aged $12-18$ years were obtained in all cases. Since the first author/investigator was also the primary care physician, prospective participants were reassured that refusal to participate will not affect treatment of their children in any manner. It should be noted that three potential participants refused to participate thus indicating that this reassurance was communicated clearly.

Data collection took place in the dialysis unit while the child was undergoing dialysis to avoid any extra visits thus ensuring participants' convenience and in a closed office space to maintain privacy. The obtained data was provided unique identification codes to preserve confidentiality. Participants who screened positive for anxiety or depression were offered priority, free-of-cost consultation by a psychiatrist at SIUT.

\section{Data analysis}

The quantitative data were recorded and analysed using Statistical Package for Social Sciences (SPSS) version 22.0. The questionnaire mainly contained categorical variables therefore data analysis is presented in the form of descriptive statistics including frequencies, percentages and mean values accompanied with standard deviation and range. Inferential statistics were not performed since the sample size was too small to provide any meaningful results.

During manuscript writing, the data were revisited, with the two authors reaching mutual agreement upon themes after discussion. Case studies are presented in a narrative form in the Results section with appropriate reflections included within the Discussion section.

\section{Results}

\section{Participant demographics}

The demographic profile of 52 caregivers is summarised in Table 1. The mean age of mothers was $40.7 \pm 7.4$ (24 - 55) years, while the fathers' mean age was $47 \pm 8.6(30-66)$ years. Forty-six (88\%) of mothers were healthy, and 29 (66\%) were uneducated or had received education up to 5 grades only $(n=5)$. Forty-one (81\%) fathers were healthy and $37(43 \%)$ had received education up to 5 th grade or more. Forty-four (84\%) of these mothers were housewives while 16 (31\%) and 15 (29\%) of the fathers were working as salaried professionals and skilled workers, respectively.

The demographic profile of children receiving dialysis and the education status of these children and their siblings is summarised in Table 2. The mean age of the children receiving dialysis was 15.27 (range: 12-18) years, and on an average, they were on dialysis for 4 years. There were 28 boys and 24 girls in this cohort. Seventy-seven percent of the children were unable to get a transplant due to unavailability of live-related kidney donors.

\section{Socioeconomic impact of dialysis}

The socioeconomic status of these families, along with the indirect costs borne by the families especially to commute to the hospital are tabulated in Table 3. The median monthly household income was Pakistani Rupees (PKR) 24,000 (USD 2880) annually, with $80 \%$ of the families having a household income ranging between PKR 11,000 to 50,000 (USD 110500) monthly. In 32 (62\%) of the families, there was only one breadwinner, most commonly the father. Thirty-five percent of families had to migrate because dialysis facilities were not available in their city. Most of them used public transportation or rickshaws to commute to hospital, travelling up to $50 \mathrm{~km}$, at a cost of PKR $536 \pm 470$ (USD $5 \pm 4$ ) and spending 6 to 8 hours in traveling to a session on an average.

To overcome the financial challenges, some families had to take extraordinary measures to generate other sources of income such as selling off their cattle, taking loans, getting help from relatives and neighbours, and renting out portions of their homes. In one family, the maternal grandmother of the child had to resort to begging to help her daughter with the additional financial burden that had befallen the family due to the child's illness.

\section{Impact on children's education}

Seventy-seven percent of the children were receiving some kind of formal education before the initiation of dialysis, but after their treatment began, $91 \%$ of the children were deprived of education. When asked about the reason for this, more than $90 \%$ primary caretakers reported poor health. Others also stated that this was because time spent on travelling for dialysis resulted in missing many school days making it difficult for children to cope with their studies. Another parent voiced her concern about the child going to school, "He has to carry such a huge bag when he goes to school, and climb many stairs." Another mother added, "I feel very scared. You know he has a fistula on his hand. What if he gets hurt?" Two parents, on the other hand, gave financial difficulties as the reason for discontinuing the child's education.

In $35 \%$ of the families, the education of other siblings was seriously affected because of the ongoing dialysis of one sibling in the family primarily because siblings too had to drop out of school after the initiation of dialysis.

\section{Psychological impact of caregiving}

The validated questionnaire used for screening the anxietydepression complex identified 19 (37\%) primary caretakers with a score of more than 20, signifying the presence of symptoms of anxiety and depression. These questionnaires were reviewed by a psychiatrist at the institute, and those who mainly presented with somatic complaints were excluded. Eight (15\%) caretakers were offered free psychiatric evaluation, of whom only two agreed to seek help. However, when asked about suicidal ideation/suicide, a majority of the caretakers responded with "Haraam 
Table 1: Demographic characteristics of participants' parents



[forbidden]" believing that such an act was one of "cowardice." Participants also negated the impact of their symptoms by stating "Alhumdilllah [Thank God]."

\section{Presence of external support}

Eighty-one percent of the families lived in nuclear settings. However, in $90 \%$ of the cases there were multiple family members providing extra support to the parents. This included elder siblings and grandparents who looked after the house when the parents were away with the sick child for dialysis sessions. In some cases, the neighbours helped, and in one instance, the landlord looked after the younger siblings when the mother was away with the child for dialysis sessions.

\section{Case studies}

Case study 1

Shehnaz ${ }^{*}, 48$ years old, is Aasia's mother. Aasia, now 18 years 
Table 2: Socio-demographic profile of children undergoing dialysis and of their siblings

\begin{tabular}{|c|c|c|}
\hline \multicolumn{3}{|c|}{ Demographic information of children on dialysis [N = 52] } \\
\hline \multicolumn{3}{|l|}{ Age at initiation of dialysis (in years) [n (\%)] } \\
\hline $1-5$ & \multicolumn{2}{|l|}{$4(7.7 \%)$} \\
\hline $6-12$ & \multicolumn{2}{|l|}{$33(63.4 \%)$} \\
\hline $13-18$ & \multicolumn{2}{|l|}{$15(29 \%)$} \\
\hline Mean \pm Standard deviation (range) & \multicolumn{2}{|l|}{$10.55 \pm 3.2(3-17)$} \\
\hline \multicolumn{3}{|l|}{ Gender [n (\%)] } \\
\hline Male & \multicolumn{2}{|l|}{$28(53.8 \%)$} \\
\hline Female & \multicolumn{2}{|l|}{$24(46.2 \%)$} \\
\hline \multicolumn{3}{|l|}{ Years on dialysis } \\
\hline Mean \pm Standard deviation (range) & \multicolumn{2}{|l|}{$4.65 \pm 3.27(1-14)$} \\
\hline \multicolumn{3}{|l|}{ Reason for no Transplant [n (\%)] } \\
\hline No available donor & \multicolumn{2}{|l|}{$40(76.9 \%)$} \\
\hline Psychiatric or mental ailment & \multicolumn{2}{|l|}{$4(7.6 \%)$} \\
\hline De novo disease & \multicolumn{2}{|l|}{$4(7.6 \%)$} \\
\hline Physical complications of ESKD & \multicolumn{2}{|l|}{$3(5.8 \%)$} \\
\hline No willing donor & \multicolumn{2}{|l|}{$1(1.9 \%)$} \\
\hline Education status of children on dialysis [n (\%)] & Before HD & After HD \\
\hline Going to school & $41(79 \%)$ & $5(8 \%)$ \\
\hline Not receiving any formal education & $11(21 \%)$ & $47(92 \%)$ \\
\hline Reasons for no education & $(n=11)$ & $(n=47)$ \\
\hline Poor health & $6(50 \%)$ & $43(91 \%)$ \\
\hline Mentally weak & $3(25 \%)$ & $2(4 \%)$ \\
\hline Financial issues & $1(8 \%)$ & $2(4 \%)$ \\
\hline Too young to start & $1(8 \%)$ & - \\
\hline No tradition of sending girls to school & $1(8 \%)$ & - \\
\hline \multicolumn{3}{|l|}{ Impact of dialysis on education of siblings } \\
\hline No effect on education of siblings & \multicolumn{2}{|l|}{$36(65 \%)$} \\
\hline Education affected due to dialysis (Total) & \multicolumn{2}{|l|}{$18(35 \%)$} \\
\hline Did not go to school at all & \multicolumn{2}{|l|}{$8(15 \%)$} \\
\hline Dropped out of school & \multicolumn{2}{|l|}{$5(10 \%)$} \\
\hline Poor performance & \multicolumn{2}{|l|}{$3(6 \%)$} \\
\hline Could not go for higher education & \multicolumn{2}{|l|}{$2(4 \%)$} \\
\hline
\end{tabular}

Notes: ESKD: End-stage kidney dialysis; HD: haemodialysis. 
Table 3: Household structure and means of financing expenditure for dialysis of children $(\mathbf{N}=\mathbf{5 2})$

\begin{tabular}{|c|c|}
\hline \multicolumn{2}{|l|}{ Number of Bread winners } \\
\hline 1 & $32(62 \%)$ \\
\hline 2 & $11(21 \%)$ \\
\hline 3 or more & $9(18 \%)$ \\
\hline \multicolumn{2}{|l|}{ Household monthly income, (in PKR) } \\
\hline Mean & $28,588 \pm 21,159($ USD $274 \pm 203)$ \\
\hline Median & 24000 (USD 230) \\
\hline Less than 10,000 (USD 100) & $5(10 \%)$ \\
\hline 11,000 to 25000 (USD $110-250)$ & $24(46 \%)$ \\
\hline 26000 to 50000 (USD $260-500)$ & $18(34 \%)$ \\
\hline More than 50,000 (USD > 500) & $5(10 \%)$ \\
\hline \multicolumn{2}{|l|}{ Primary Breadwinner } \\
\hline Father & 37 (71\%) \\
\hline Mother & $2(4 \%)$ \\
\hline Brother & $3(6 \%)$ \\
\hline Joint family & $7(13 \%)$ \\
\hline Uncles and grandparent & $3(6 \%)$ \\
\hline \multicolumn{2}{|l|}{ Other sources of income } \\
\hline No additional source & $33(63 \%)$ \\
\hline Contribution by other family members & $10(19 \%)$ \\
\hline Rent from a shop/agricultural land/portion of house & $4(8 \%)$ \\
\hline Sold house/cattle & $2(4 \%)$ \\
\hline Support from NGO/Community members & $2(4 \%)$ \\
\hline Grandparent begs on street & $1(2 \%)$ \\
\hline \multicolumn{2}{|l|}{ Family structure } \\
\hline Nuclear Family & $42(81 \%)$ \\
\hline Joint Family & $10(19 \%)$ \\
\hline \multicolumn{2}{|l|}{ Change of permanent address due to dialysis } \\
\hline Yes & $18(34 \%)$ \\
\hline No & $34(66 \%)$ \\
\hline \multicolumn{2}{|l|}{ Distance travelled } \\
\hline 0 to $25 \mathrm{~km}$ & $13(25 \%)$ \\
\hline 26 to $50 \mathrm{~km}$ & $34(65 \%)$ \\
\hline More than $50 \mathrm{~km}$ & $5(10 \%)$ \\
\hline \multicolumn{2}{|l|}{ Means of Transportation } \\
\hline Public Bus & $22(42 \%)$ \\
\hline Rickshaw ** & $15(28 \%)$ \\
\hline Motorcycle & $9(17 \%)$ \\
\hline Car & $6(13 \%)$ \\
\hline \multicolumn{2}{|l|}{ Average time spent in hospital per session } \\
\hline Less than 6 hours & $3(6 \%)$ \\
\hline 6 to 8 hours & 31 (59\%) \\
\hline 8 to 10 hours & $10(19 \%)$ \\
\hline More than 10 hours & $8(16 \%)$ \\
\hline \multicolumn{2}{|l|}{ Note: } \\
\hline \multicolumn{2}{|c|}{ *USD conversion rates are according to the market value at the time of study. } \\
\hline \multicolumn{2}{|c|}{ ** Rickshaw is a 3 wheeled scooter with capacity of 1 to 3 passengers. A common relatively low cost rented mode of transportation in Pakistan. } \\
\hline \multicolumn{2}{|l|}{ PKR:Pakistani rupees } \\
\hline
\end{tabular}


of age, has been coming to SIUT for dialysis since she was four years old. Apart from ESKD, she also has impaired vision and hearing. Shehnaz originally hails from a poor family in a small town of Sindh, about $200 \mathrm{~km}$ north of Karachi. Married when she was 20 years old to her paternal uncle's son, Ahmed, a daily wager, she has undergone unimaginably difficult times.

Ahmed passed away when he was 45 years old, leaving her with seven children suffering from numerous health issues. Shehnaz's eldest son, Latif died when he was 14 years old due to kidney failure. Her daughter, Yasmeen could only study until the 10th grade, and since then has been helping her mother with household chores and taking care of her younger siblings. Yasmeen has recently been diagnosed with kidney failure but does not require dialysis at the time. Shehnaz's son, Nasir, has post meningitis sequelae acquired in early childhood requiring special attention. Another son, Dilshad could not continue regular school because of learning difficulties combined with a stutter, and now works with a local mechanic. Hamid is her youngest son, and goes to school.

Throughout these difficulties times, Shehnaz has drawn support from her father-in-law and paternal uncle. They live in a joint family system, and her basic financial needs are covered by her family.

She faces numerous issues in her commute to the hospital for Aasia's dialysis since all the earning male members of the family work on daily wages. After Ahmed passed away, the family decided to discontinue Aasia's dialysis. However, one day, "Asya ko jhatke lage, aur woh behosh hogaye. Mujh say dekha nahi gaya; mein usko Karachi le aye buss mein baith kay [One day, Aasia had a seizure and fell unconscious. I could not bear this; I immediately came to Karachi in a bus]". When she was unable to pay for the bus ride, the conductor took pity on her seeing her daughter's miserable condition.

At SIUT, Aasia was admitted to the ICU in a critical condition. She required mechanical ventilation but after almost one week, Aasia was back to her original state of health. Her grandfather came on the third day to inquire about their condition and then left. When Aasia was discharged, Shehnaz did not have enough money to take her home.

She took this problem to the doctor who took care of Aasia in the ICU. In her own words,

Doctor sahib ki ankhon me ansoo aa gaye. Unho ne us waqt jaib se ek hazar rupay nikal kur mujhe diye aur kaha ke ab hur maheene aap mujh se ye paise le lijye ga. Wo waqt hai aur aaj is baat ko 8 saal ho gai hai, wo pabandi se mujhe pehli tareekh ko paise dete hain." [The doctor had tears in his eyes. He immediately took out a 1000-rupee note (USD6) and gave it to me. He told me to take money from him every month. It has been 8 years now and he regularly gives me money on the first of every month].

Since then, a transporter has made special arrangement for
Shehnaz to ride on specific buses with payment of just one seat with one-way tariff for a return trip. Shehnaz is grateful and has no regrets with continuing her daughter for dialysis, except:

Bus agar afssos hai to meri beti Yasmeen ke liye. Us ne kabhi aam bachon jesi zindagi guzari hi nahi. Humesha ghar ka khayal hi rukha. Ab meri bohat khwahish he ke us ki shadi ho jai leken koi humare ghar rishta nahi bhejta. Kehte hain in ke ghar me beemari hai [The only regret I have is for my daughter Yasmeen. She has never lived a normal child's life. She has always taken care of the house. I wish that she could get married but nobody sends us a proposal. They say that we have disease in our family]

\section{Case study 2}

Samina, 30 years of age, is the primary caretaker of her youngest brother, Hamza, who has been on dialysis since the past five years. The entire family lived in their own house located in a katchi abadi [slum] in Karachi. She has two older brothers and two older sisters, and three younger brothers, and two younger sisters. The older brothers and sisters moved out of the family house after marriage. Soon after their marriages, both of Samina's parents died within a span of a few months, which positioned Samina as the head of the household.

When Hamza was initially diagnosed with the disease, the married siblings came forward to help. However, once they realised the chronic nature of the illness and the need for kidney transplant, their support gradually declined. The remaining members of the family including Hamza work to take care of the financial needs of the family. The brothers work as salespersons in a shop, while the sisters stitch clothes for a garment factory from home. Hamza has a small portable shop and sells chocolates, biscuits and other such goodies to children in the neighbourhood.

When Hamza was evaluated for transplant, his blood group matched only with his eldest brother, Rahim and youngest sister, Farah. Rahim refused to donate because he was afraid that donating a kidney would make him sick, as well. Married with two children, he believed his primary responsibility was towards his own children. Farah was 20 years old and single. Since the well-being of the donor is a top priority in every live-related transplant programme, Farah was not considered as an ideal candidate for donation. In SIUT's experience, single women who donate kidneys are stigmatised and may have difficulty in getting married. The family therefore decided that Hamza would continue on dialysis until Rahim changed his mind.

During this time, Hamza acquired Hepatitis $C$, and did not respond well to the treatment due to side effects including fevers, body aches, and psychiatric complications such as agitation, and hallucinations. Samina recalls those times when it became extremely difficult for the family to take care of him. The financial burden also increased drastically 
since he required multiple out of schedule hospital visits. The siblings at home sacrificed their own needs, sharing additional household expenses.

When asked whether she ever thought about giving up Hamza's care, and living her own life,

Doctor sahib, kisi ko qurbani deni partee hai. Agar hamaray waldeen aaj hotay tou alag baat hoti. Agar mein himmat chordun, tou kon khayaal rakheyga isska? [ someone has to sacrifice If our parents had been alive, it would have been different. Now if I give up, who will look after him? ]" She believed that her faith in God, "Buss mein dua mangteen hun [I pray to God]" allowed her to cope well with difficulties life had thrown at her, stating "Mujhe apne Khuda per poora yaqeen hai. Wo kisi ko us ki bardasht se ziyada takleef nahi deta [I firmly believe in my God. I don't think He gives us more pain than we can endure.]

\section{Discussion}

This pilot study represents a single-centre experience of a tertiary care public sector hospital situated in a developing country where a large number of patients live below the poverty line.

One of the biggest burdens families face after initiation of paediatric dialysis is the financial one that goes well beyond the actual treatment costs. In developed countries, despite universal health coverage or adequate health insurance schemes, parents still report a significant financial burden, including parental inability to work efficiently, and difficulties encountered in working overtime (8). Poor outcomes in families with low socioeconomic status have been reported in studies from countries with high GDP like the Netherlands (32), Saudi Arabia (11), New Zealand (33), the United States (34) and Canada (35).

The current study showed that for low-income families, high transportation costs (particularly when commuting from other towns/cities) made the supposedly "free" dialysis unaffordable. Reported financial challenges included having to borrow money, and selling off livestock to bear other expenses such as costs of relocation and transport expenditure associated with hospital visits at least twice a week. For such families, an illness can send the entire household into a financial catastrophe (36).

Geographic inaccessibility of dialysis facilities also compounds the problem (37). The majority of dialysis centres tend to be situated in urban areas requiring long commutes for people living in rural areas, as well as permanent relocation to urban centres for some families. Long commutes not only carry a financial cost but also require caregivers to take time off from work resulting in a high opportunity cost.

The study revealed that one-third of the families had to change their permanent address after the initiation of the child's dialysis. To move to a mega-city without sufficient resources, the entire family has to make sacrifices. Finding a nearby residence, job and educational facility for other siblings also prove extremely challenging. Previous studies have also documented that following the diagnosis of a chronic illness, caregivers experience disruption in their daily schedule (38). A study conducted in India also indicated that families temporarily relocate to other cities but with the potential consequence of loss of livelihood for the entire family (39).

Unless health policymakers consider geographical accessibility, sustainability of dialysis treatment will always be under threat. A study from Indonesia has shown that despite the country's commitment to providing universal health coverage for dialysis services, only $13 \%$ of ESKD patients had access to dialysis services, since only 10 of the 6000 inhabited islands in the country have a haemodialysis centre (40).

SIUT has been providing free treatment for more than four decades. In recent years, with the recognition that geographic accessibility may also lead to high drop-out rates, there have been attempts to open satellite dialysis centres located in different parts of Karachi. In addition, dialysis services are also being provided in some peri-urban areas to cater to high patient volumes and reduce transportation costs for patients and their caregivers.

The study also revealed that burdens extend well beyond the financial ones. Extended social support from other family members within the kinship network may be sought, and at times, neighbours can prove to also be a source of assistance. Ninety percent caregivers in the current study had other family members providing support. Even though there were only $20 \%$ families cohabiting in a joint family setup, with a few exceptions, the whole family participated in providing care. In most cases, elder siblings or grandparents looked after the household while the parents were away at the hospital. Case Study 2 above illustrates the extent to which the elder siblings had to make sacrifices in order to ensure continuity of dialysis for their younger brother.

The presence of this social support could be one of the key contributing factors that provides strength to parents/ caretakers to continue the treatment of their child. For Shehnaz, in Case Study 1, her father-in-law and other members of the family took care of the family's basic needs. A study from Brazil also supports this finding (41). For families who lack external familial support beyond the immediate members, dropping out of the dialysis may be the only recourse.

However, the "darker" side of familial bonds and lack of support, should not be discounted. As evident in Case Study 2 , the eldest brother, who would ideally be considered the "head" of the household in the absence of parents, showed extreme reluctance to donate his kidney to the younger brother since he believed his own children were a greater priority. This has been evident from other studies in this 
institute as well. (42-43).

Physicians practising in resource-constrained settings are cognisant of such realities highlighting them as a key dilemma in their clinical practice (44). While paediatric nephrologists have a moral responsibility to ensure the benefit of their patients, who are all children with limited decision-making capacity, they are also forced to consider the social lives of the caregivers.

This brings to the fore the ethical responsibility of policymakers with respect to provision of adequate social support to parents/caregivers of these patients. This will mean that indirect and intangible costs need to be included in economic evaluations, a step which will be difficult to implement in low-income settings.

Lack of social support combined with constant stress on caregivers also makes them predisposed to psychosocial problems. The effect of a child's illness on caretakers has been researched extensively (45-47). Even in non-life-threatening skin conditions of a chronic nature, $36 \%$ of 118 parents screened positive for anxiety (48). In a study of 60 families of children on dialysis by Fielding et al (1999) in England, multiple socio-demographic factors were identified that were associated with parental anxiety and depression. Lower socioeconomic status, large families, limited support from other family members and being parents of young children were identified as higher risk factors for developing depression (49).

In the current study, almost one-third of parents screened positive for symptoms of anxiety and depression. However, more than half from this pool exhibited somatic symptoms like frequent headaches, indigestion and fatigue. This is unsurprising since in Pakistan individuals, particularly women tend to present with somatic complaints of depression and anxiety $(36,37)$. Symptoms of clinical anxiety/depression requiring psychiatric treatment were found in only $17 \%$ of caretakers.

Prevalence of depression/anxiety was expected to be much higher in this cohort due to the presence of risk factors such as lower socioeconomic status. However, low prevalence could be due to strong extended familial support (50). Another possible explanation could be the role of religious faith as a coping mechanism. Several participants stated that since suicide was forbidden in Islam, they did not consider it. In a society in which religion pervades nearly every aspect of life, religious beliefs that condemn suicide can also cushion people against the negative mental health effects of chronic conditions.

A major impact was noted on education of children. Forty-one children had been receiving some kind of formal education earlier, but after the start of the treatment, the trend was reversed with more than $90 \%$ children not getting any formal education. Poor health was cited as the factor for this. In developed countries, special arrangements in the timing of dialysis are made to facilitate children's education. Tutors are made available in the dialysis unit who ensure continuity of education (51). In developing countries, such arrangements may not be feasible or too expensive to afford.

However, it raises a question whether policymakers have a moral responsibility to ensure a multi-sectoral approach to health. This would only come with the realisation on part of the government that poor health of one individual affects those close to them $(52,53,54)$. In order to ensure overall wellbeing of paediatric patients, it is important to consider innovative approaches to providing education, perhaps within the domain of skills-based trainings that allow individuals with chronic illnesses to lead fulfilling lives.

Chronic disability and illness of one child can affect other siblings. It impacts the upbringing, mutual relationships, family dynamics and behaviour of other siblings (55-57). As this study revealed, 35\% caretakers stated that the education of other siblings was affected. While this could also be due to the cost of education in itself, since participants of this study belonged to lower SES, it also highlights the number of ways in which the lives of other children in the family may be affected (58-60).

Other significant impacts were also noted on the patients' siblings. In Case 1, Shehnaz's eldest daughter, Yasmeen was unable to live her childhood to the fullest because she had to help her mother out with household chores. Yasmeen was also unable to get married because of the stigma due to the "disease" present in her family.

Caring for a child with chronic illness therefore has farreaching consequences, figures not typically included in costs of treatment. This could be one of the reasons for high dropout rates. Although no official statistics are available from Pakistan, experience from India has demonstrated a high dropout rate of $47 \%$ in publicly funded dialysis facilities (60). Similar predicaments have been reported from Brazil and Algeria (61-62). The high dropout rate should be a cause of concern for policymakers who invest with the noblest of intentions in the provision of free treatment for patients.

It becomes important then for physicians to be sensitive to these difficulties, and respond accordingly while offering treatment choices. (7). It is therefore an ethical imperative for healthcare professionals (and the broader health system) to consider the sociocultural contexts from which patients and their families originate in order to minimise suffering.

While this study is novel in terms of its contribution to the literature from the perspective of Pakistan, there are some limitations. Since this is a pilot study with a limited sample size, the results are not generalisable. However, the case studies serve to supplement this limitation by adding a rich context. Furthermore, areas unexplored in the current work include detailed assessment of impact on siblings and role of religion as a coping mechanism, which are best addressed through a qualitative inquiry. It would also be worthwhile to look at families whose children have received kidney 
transplants and compare their quality of life with those families whose children are on dialysis.

\section{Conclusion}

The pilot study provides a glimpse into the lives of families severely impacted by to the initiation of dialysis in the kidney disease. It aims to give useful insights to physicians to deal with patients and their families in a more empathetic fashion, and to treat not only the disease, but also attempt to secure their well-being.

Disclosures: The authors declare that they have no financial and non-financial disclosures for this research.

Contributions: AL conceived and initiated the research as part of his thesis, collected and analysed the data, and wrote the manuscript. SS provided help in data analysis, and wrote the manuscript.

Statement about publication of similar work: An earlier publication by the same two authors titled, "Ethical Challenges in Dialysis and Transplantation: Perspectives from the Developing World" published in Seminars in Nephrology in May 2021 covers some of the issues addressed in the current paper. The current work served as the bedrock for the development of the Seminars publication, but the latter goes beyond into areas of transplantation as well.

Acknowledgments: The research would not have been possible without the useful and constant guidance of faculty members at CBEC, SIUT including Drs Farhat Moazam, Aamir Jafarey and Bushra Shirazi. AL would like to acknowledge his daughter, Tasneem Ali for her contributions in proofreading drafts of thesis. The authors are grateful for the help from the institute's psychiatrist, Dr Naim Siddiqui who helped in screening of caregivers for anxiety/depression.

*Note: All names in the case studies have been changed to protect the individuals' identities.

\section{References}

1. Shroff R, Rees L, Trompeter R, Hutchinson C, Ledermann S. Long-term outcome of chronic dialysis in children. Pediatr Nephrol. 2006;21(2): 257-64. Doi: 10.1007/s00467-005-2067-6.

2. Goldstein SL, Rosburg NM, Warady BA, et al. Pediatric end stage renal disease health-related quality of life differs by modality: a PedsQL ESRD analysis. Pediatr Nephrol. 2009 Aug;24(8):1553-1560. Available from: https://pubmed.ncbi.nlm.nih.gov/19421787/

3. Chandar J, Chen L, Defreitas M, Ciancio G, Burke G. Donor considerations in pediatric kidney transplantation. Pediatr Nephrol. 2020 Jan 13 [cited 2020 Nov 19]:1-3. Available from: https:// link.springer.com/article/10.1007/s00467-019-04362-z

4. Peruzzi L, Amore A, Coppo R. Challenges in pediatric renal transplantation. World J Transplant. 2014 Dec 24[cited 2020 Jun18];4(4): 222. Available from: https://www.ncbi.nlm.nih.gov/pmc/articles/ PMC4274593/

5. Tong A, Lowe A, Sainsbury P, Craig JC. Experiences of parents who have children with chronic kidney disease: a systematic review of qualitative studies. Pediatrics. 2008 Feb;121(2):349-360.

6. Fischbach M, Edefonti A, Schröder C, Watson A; European Pediatric Dialysis Working Group. Hemodialysis in children: General practical guidelines. Pediatr Nephrol 2005 Aug[cited 2020 Jun 18];20:1054-66. Availablefrom:https://www.ncbi.nlm.nih.gov/pmc/articles/ PMC1766474/

7. Bignall OR, Goldstein SL. Childhood CKD affects the entire family. AM J Kidney Dis. 2015 Mar 1[cited 2020 Jun 18];65(3):367-8. Available from:
https://linkinghub.elsevier.com/retrieve/pii/S0272638614014681

8. Medway M, Tong A, Craig JC, Kim S, Mackie F, McTaggart S. et al. Parental Perspectives on the Financial Impact of Caring for a Child with CKD. Am J Kidney Dis. 2015 Mar;65(3):384-393. Doi: 10.1053/ j.ajkd.2014.07.019

9. Thyen U, Sperner J, Morfeld M, Meyer C, Ravens- Sieberer U. Unmet Health Care Needs and Impact on Families of Children with Chronic Disabilities in Germany. Ambul Pediatr. 2003;3:74-81. Doi: 10.1367/1539-4409(2003)003<0074:uhcnai>2.0.co;2

10. Tsai TC, Liu SI,Tsai JD, Chou LH. Psychosocial effects on caregivers for children on chronic peritoneal dialysis. Kidney Int. 2006 Dec[cited 2020 Jun18];70:1983-1987. Available from: https:// linkinghub.elsevier.com/retrieve/pii/S0085-2538(15)51872-3

11. Kari JA, Alzharany M, El-Deek B, Maimani M, El-Desoky S. Social impact of dialysis on children and their families. Indian J Pediatr. 2014 Oct;81(10):1020-1026. Available from: https:// link.springer.com/article/10.1007/s12098-013-1236-z

12. Medicare.gov The Official US Government Site for Medicine. Dialysis services and supplies [cited 2020 Jun 18]. Available from: https:// www.medicare.gov/coverage/dialysis-services-supplies

13. The World Bank. Current health expenditure \% of GDP [cited 2020 Jun 18]. Available from: https://data.worldbank.org/indicator/ SH.XPD.CHEX.GD.ZS

14. Asian Development Bank. Poverty in Pakistan [cited 2020 June 18]. Available from: https://www.adb.org/countries/pakistan/poverty

15. The World Bank. Out of pocket expenditure- Pakistan [cited 2020 June 18]. Available from: https://data.worldbank.org/indicator/ SH.XPD.OOPC.CH.ZS?locations=PK

16. Teerawattananon Y, Dabak SV, Khoe LC, Bayani DB, Isaranuwatchai $W$. To include or not include: renal dialysis policy in the era of universal health coverage. BMJ. 2020 Jan[cited 2020 Jun 18] 28;368. Available from: https://www.bmj.com/content/368/bmj.m82

17. Ashuntantang G, Osafo C, Olowu WA, Arogundade F, Niang A, Porter $\mathrm{J}$, et al. Outcomes in adults and children with end-stage kidney disease requiring dialysis in sub-Saharan Africa: a systematic review. Lancet Glob Health. 2017 Apr 1[cited 2020 Jun 18];5(4):e408-17. Available from: https://www.thelancet.com/pdfs/journals/langlo/ PIIS2214-109X(17)30057-8.pdf

18. Kaur G, Prinja S, Ramachandran R, Malhotra P, Gupta KL, Jha V. Cost of hemodialysis in a public sector tertiary hospital of India. CKJ. 2018 Oct [cited 2020 Jun 18];11(5):726-33. Available from: https:// academic.oup.com/ckj/article/11/5/726/4825049

19. Mazhar F, Nizam N, Fatima N, Siraj S, Rizvi SA. Problems Associated With Access to Renal Replacement Therapy: Experience of the Sindh Institute of Urology and Transplantation. Exp. Clin. Transplant. 2017 Feb1;15(Suppl1):46-9.Availablefrom:https:// pubmed.ncbi.nlm.nih.gov/28260431/

20. Mushi L, Marschall P, Fleßa S. The cost of dialysis in low and middleincome countries: a systematic review. BMC Health Serv Res. 2015 Jun;15(1):1-0. Available from: https://link.springer.com/article/ 10.1186/s12913-015-1166-8

21. Suja A, Anju R, Anju V, Neethu J, Peeyush P, Saraswathy R. Economic evaluation of end stage renal disease patients undergoing hemodialysis. J Pharm Bio allied Sci. 2012 Apr;4(2):107-11. Doi: 10.4103/0975-7406.94810.

22. Ramachandran R, Jha V. Kidney transplantation is associated with catastrophic out of pocket expenditure in India. PLoS One. $2013 \mathrm{Jul}$ 4[cited 2020 Jun 18];8(7):67812. Available from: https:// journals.plos.org/plosone/article?id=10.1371/journal.pone. 0067812

23. Ojo A. Addressing the global burden of chronic kidney disease through clinical and translational research. Trans Am Clin Climatol Assoc. 2014[cited 2020 Jun 18]. 125:229-243. Available from: https:// www.ncbi.nlm.nih.gov/pmc/articles/PMC4112688/

24. Teh JC, Frieling ML, Sienna JL, Geary DF. Attitudes of caregivers to management of end-stage renal disease in infants. Perit Dial Int: J Int Soc Perit Dial. 2011 Jul [cited 2020 Jun 18]. 31:459-465. Available from:https://journals.sagepub.com/doi/abs/10.3747/pdi. 2009.00265

25. Geary DF. Attitudes of pediatric nephrologists to management of end-stage renal disease in infants. J Pediatr. 1998 Jul. 133(1):154156. Available from: https://www.sciencedirect.com/science/article/ abs/pii/S0022347698701994

26. Linder E, Burguet A, Nobili F, Vieux R. Neonatal renal replacement therapy: an ethical reflection for a crucial decision. Arch Pediatr. 2018 Aug[cited 2020 Jun 18];25(6):371-377. Available from: https://www.sciencedirect.com/science/article/abs/pii/ S0929693X18301386 
27. Fauriel I, Moutel G, Moutard ML, Montuclard L, Duchange N, Callies I, Francois I, Cochat P, Herve C. Decisions concerning potentially lifesustaining treatments in paediatric nephrology: a multicentre study in French-speaking countries. Nephrol, Dial, Transpl: Off Publication of the European Dialysis and Transplant Association - European Renal Association. 2004. 19:1252-1257

28. Garcia-Garcia G, Harden P, Chapman J. The global role of kidney transplantation. Indian J Nephrol 2012[cited 2020 Jun 18];22:77-82. Available from: https://www.indianjnephrol.org/text.asp? 2012/22/2/77/97101

29. Shah HB, Atif I, Rashid F, Babar MW, Arshad F, Qamar W, Khan OA, Qadir ML. Assessment of caregiver burden of patients receiving dialysis treatment in Rawalpindi. J Pakistan Med Assoc. 2017 Oct 1[cited 2020 Jun 18];67(10):1498-501. Available from: https://www.jpma.org.pk/ article-details/8383?article_id=8383

30. Sindh Institute of Urology and Transplantation. Statistics [cited 2020 June 18]. Available from: https://siut.org/statistics-gallery.php

31. Ali BS, Reza H, Khan MM, Jehan I. Development of an indigenous screening instrument in Pakistan: the Aga Khan University Anxiety and Depression Scale. J Pak Med Assoc. 1998;48(9):261. Available from: https://pubmed.ncbi.nlm.nih.gov/10028792/

32. Groothoff JW, Gruppen MP, Offringa M, et al. Mortality and causes of death of end-stage renal disease in children: A Dutch cohort study. Kidney Int. 2002 Feb [cited 2020 Jun 18]; 61(2):621-629. Available from: https://www.sciencedirect.com/science/article/pii/ S0085253815482535

33. Walker RC, Howard K, Tong A, Palmer S C, Marshall M R and Morton R L. The economic considerations of patients and caregivers in choice of dialysis modality. Hemo Int, 2016 Oct[cited 2020 Jun 18];20(4):634642. Available from: https://onlinelibrary.wiley.com/doi/full/10.1111/ hdi.12424

34. Hidalgo G, Ng DK, Moxey-Mims M, et al. Association of income level with kidney disease severity and progression among children and adolescents with CKD: a report from the Chronic Kidney Disease in Children (CKiD) Study. Am J Kidney Dis. 2013 [cited 2020 Jun 18];62(6): 1087-1094. Available from: https://www.sciencedirect.com/science/ article/abs/pii/S0272638613009918

35. Danderson D, Dumont S, Jacobs P, Azzaria L. The Personal Costs of Caring for a Child with a Disability: A Review of the Literature. Pub Health Rep. 2007[cited 2020 Jun 18];122 (1):3-16. Available from: https://www.ncbi.nlm.nih.gov/pmc/articles/PMC1802121/

36. World Health Organization. Designing Health Financing Systems to reduce Catastrophic Health Expenditure [cited 2020 June 18]. Available from: https://www.who.int/health_financing/pb_2.pdf

37. Van Biesen $\mathrm{W}$, Jha V, Abu-Alfa AK, Andreoli SP, Ashuntantang G, Bernieh $B$, et al. Considerations on equity in management of endstage kidney disease in low-and middle-income countries. Kidney Int Suppl. 2020 Mar 1[cited 2020 Jun 18];10(1):63-71. Available from: https://www.ncbi.nlm.nih.gov/pmc/articles/PMC7031686/

38. Wightman A, Zimmerman CT, Neul S, et al. Caregiver Experience in Pediatric Dialysis. Pediatrics. 2019 Feb [cited 2020 Jun 18]; 143(2): e20182102. Available from: https://pediatrics.aappublications.org/ content/143/2/e20182102

39. Jha V. End-stage renal care in developing countries: the India experience. Ren Fail. 2004 Jan 1[cited 2020 Jun 18];26(3):201-8. Available from: https://www.tandfonline.com/doi/full/10.1081/JDI120039516

40. Prodjosudjadi W, Suhardjono A. End-stage renal disease in Indonesia: treatment development. Ethn Dis. 2009 Mar 1[cited 2020 Jun 18];19(1): 33. Available from: https://www.ethndis.org/priorsuparchives/ethn19-01s1-33.pdf

41. de Paula ÉS, Nascimento LC, Rocha SM. The influence of social support on strengthening families of children with chronic renal failure. Rev Lat Am Enfermagem. 2008 Aug[cited 2020 Jun 18];16(4):692-9. Available from: http://www.scielo.br/scielo.php?pid=S0104$11692008000400007 \&$ script $=$ sci_arttext

42. Naqvi SA, Rizvi SH. Constraints in living donor kidney transplantation. Transplant Proc. 2000; 32(7):1483-4. Doi:10.1016/S00411345(00)01299-9

43. Jawad F, Hussain Z, Ahmed E, Akhtar F, Hussain M. Problems of donor selection in a living related renal transplant program. Transplant Proc. 1998; 30(7):3463.

44. Mani MK. Ethical problems in renal transplantation: a personal view. Indian J. Med. Ethics.1995 Jul-Sep[cited 2020 Jun 18]; 3(3):39-41. Available from: https://ijme.in/articles/ethical-problems-in-renaltransplantation-a-personal-view/?galley=html

45. Holm, K. E., Patterson, J. M., Rueter, M. A., \& Wamboldt, F. Impact of uncertainty associated with a child's chronic health condition on parents' health. Fam Sys, \& Health. 2008[cited 2020 Jun 18]; 26(3), 282-
295. Available from: https://europepmc.org/article/MED/20490375

46. Cousino MK, Hazen RA. Parenting Stress Among Caregivers of Children with Chronic Illness: A Systematic Review.J Ped Psychology. 2013 Sep [cited 2020 Jun 18]; 38(8):809-828. Available from: https:// academic.oup.com/jpepsy/article/38/8/809/919245

47. La Clare, HL. The Impact of Childhood Chronic Illness on the Family: Psychosocial Adjustment of Siblings. 2013[cited 2020 Jun 18]. Retrieved from Sophia, the St. Catherine University repository website: https://sophia.stkate.edu/msw_papers/218

48. Manzoni AP, Weber MB, Nagatomi AR, Pereira RL, Townsend RZ, Cestari TF. Assessing Depression and Anxiety in the Caregivers of Pediatric Patients with Chronic Skin Disorders. Anais Brasil Derma. 2013 Dec [cited 2020 Jun 18];88(6):894-899. Available from: https:// www.ncbi.nlm.nih.gov/pmc/articles/PMC3900338/

49. Fielding D, Brownbridge G. Factors related to psychosocial adjustment in children with end stage renal failure. Ped Nephrol. 1999 Nov [cited 2020 Jun 18] 13:766-770. Available from: https:// link.springer.com/article/10.1007/s004670050695\#citeas

50. Forouhari S, Teshinizi SH, Ehrampoush $\mathrm{MH}$ et al. Relationship between Religious Orientation, Anxiety, and Depression among College Students: A Systematic Review and Meta-Analysis. Iran J Public Health. 2019 Jan [cited 2020 Jun 18]; 48(1): 43-52. Available from: https://www.ncbi.nlm.nih.gov/pmc/articles/PMC6401585/

51. Warady BA, Alicia M. Neu AM, Schaefer F. Optimal Care of the Infant, Child, and Adolescent on Dialysis: 2014 Update. Am J Kidney Dis. 2014 Jun[cited 2020 Jun 18];64(1):128-142. Available from: https:// www.sciencedirect.com/science/article/abs/pii/ S0272638614005241

52. Grinyer A. The biographical impact of teenage and adolescent cancer. Chronic IIIn. 2007 Dec [cited 2020 Jun 18];3(4):265-77. Available from: https://journals.sagepub.com/doi/abs/ 10.1177/1742395307085335

53. Atkin K, Ahmad WI. Living a 'normal'life: young people coping with thalassaemia major or sickle cell disorder. Soc Sci Med. 2001 Sep 1[cited 2020 Jun18];53(5):615-26. Available from: https:// www.sciencedirect.com/science/article/abs/pii/ S0277953600003646

54. Lavigne JV, Ryan M. Psychological adjustment of siblings of children with chronic illness. Pediatrics.1979 April[cited 2020 Jun 18];63(4): 616-627. Available from: https://publications.aap.org/pediatrics/ article-abstract/63/4/616/49839/Psychologic-Adjustment-ofSiblings-of-Children

55. Stewart DA, Stein A, Forrest GC, Clark DM. Psychological adjustment in siblings of children with life threatening illness: a research note. J Child P Psychiatry.1992 May[cited 2020 Jun 18]; 33(4): 779-784. Available from: https://acamh.onlinelibrary.wiley.com/doi/abs/ 10.1111/j.1469-7610.1992.tb00913.x

56. McKeever P. Siblings of chronically ill children: a literature review with implications for research and practice. Am J Orthopsych. 1983[cited 2020 Jun 18];53(2):209-218. Available from: https:// psycnet.apa.org/record/2013-42332-003

57. Lobato D, Faust D, Spirito A. Examining the effects of chronic disease and disability on children's sibling relationships. J Ped Psych. 1988 Sep[cited 2020 Jun 18];13(3):389-407. Available from: https:// academic.oup.com/jpepsy/article-abstract/13/3/389/1222310? redirectedFrom $=$ fulltext

58. La Clare HL. The Impact of Childhood Chronic Illness on the Family: Psychosocial Adjustment of Siblings. 2013[cited 2020 Jun 18]. Retrieved from Sophia, the St. Catherine University repository website: https://sophia.stkate.edu/msw papers/218/

59. Wilson M. Families with Severe Medical Conditions in Children: Effects and Interventions. 2014[cited 2020 Jun 18]. Retrieved from Sophia, the St. Catherine University repository website: : https:// sophia.stkate.edu/msw_papers/411

60. Shaikh M, Woodward M, John O, Bassi A et al. Utilization, costs, and outcomes for patients receiving publicly funded hemodialysis in India. Kidney Int. 2018 Sep[cited 2020 Jun 18];94(3):440-5. Available from: https://www.kidneyinternational-online.org/article/S00852538(18)30332-6/fulltext

61. Salah H. An overview of renal replacement therapy in Algeria. Saudi J Kidney Dis Transpl. 1994;5(2):190-2. Available from: https:// www.sjkdt.org/article.asp?issn=1319-

2442; year $=1994$; volume $=5$;issue $=2$; ppage $=190$;epage $=192$; aulast $=$ Salah

62. Kher V. End-stage renal disease in developing countries. Kidney Int 2002 Jul[cited 2020 Jun 18];62(1):350-62. 20. Available from: https:// www.kidney-international.org/article/S0085-2538(15)48558-8/ fulltext 